\title{
NOTICE:
}

This is the peer reviewed version of the following article:

Abuelo, A., Hernández, J., Benedito, J. and Castillo, C. (2015), A pilot study to compare oxidative status between organically and conventionally managed dairy cattle during the transition period. Reproduction in Domestic Animals. [doi: 10.1111/rda.12519].

This article may be used for non-commercial purposes in accordance With Wiley Terms and Conditions for self-archiving'.

\section{A Pilot Study to Compare Oxidative Status between Organically and Conventionally Managed Dairy Cattle During the Transition Period.}

Ángel Abuelo*, Joaquín Hernández, José L. Benedito, Cristina Castillo

Department of Animal Pathology, College of Veterinary Medicine, University of Santiago de Compostela.

Correspondence : Dr. Ángel Abuelo. Departamento de Patología Animal. Facultad de Veterinaria. Campus Universitario s/n. 27002 - Lugo (Spain) angel.abuelo@usc.es; angel.abuelo.sebio@gmail.com

Short title: Oxidative status in organic dairy cows 
1

2 The aim of this study was to assess the redox balance of organically managed dairy

3 cattle $(\mathrm{OMC} ; \mathrm{n}=40)$ during the transition period and to compare this with conventionally

4 managed cattle $(\mathrm{CMC} ; \mathrm{n}=22)$. Serum samples of dairy cows from two organic and one

5 conventional farm were taken. Markers of oxidants production [reactive oxygen species]

6 and total serum antioxidant capacity were measured in four different production stages:

7 (i) far-off dry (2 to 1 months before calving; 44 samples in CMC and 48 in OMC); (ii)

8 close-up dry (1 month until 3 days before calving; 44 CMC; 54 OMC); (iii) fresh (3 days

9 to +1 month after calving; $44 \mathrm{CMC}$; $49 \mathrm{OMC}$ ); and (iv) peak of lactation (+1 to +3 months;

$71 \mathrm{CMC} ; 78 \mathrm{OMC})$. Values were compared between production stages and against a metabolic baseline status (4th-5th month of pregnancy; $40 \mathrm{CMC} ; 30 \mathrm{OMC}$ ). Our results indicated that throughout the periparturient period, OMC had lower concentrations of reactive oxygen species, but also a lower antioxidant capacity than $\mathrm{CMC}$. Indeed, when the two components of the redox balance were assessed together through the Oxidative Stress index, the values of this parameter were higher for OMC than for $\mathrm{CMC}$, thereby implying a higher risk of oxidative stress. Therefore, further larger studies are needed to confirm the current observations, as organically reared animals might be exposed to a lack of antioxidants supply.

Keywords: Antioxidants; Dairy cow; Farming system; Oxidative stress; Redox balance 


\section{Introduction}

Oxidative stress (OS) occurs when there is an increase in oxidant production and free radical formation that overwhelms the body's capacity to neutralize and eliminate these reactive radical forms (Sordillo and Aitken 2009). OS plays a key role in the initiation and maintenance of several pathological conditions (Lykkesfeldt and Svendsen 2007), including reproductive diseases in the cow (Rizzo et al. 2012). In addition, there is evidence that dairy cows undergo os during the transition period (Bernabucci et al. 2005; Castillo et al. 2005), which is thought to be a significant underlying factor in dysfunctional host immune and inflammatory responses, thereby increasing cows' susceptibility to health disorders (Sordillo and Aitken 2009).

In conventional intensive dairy farming, the common practice of supplementing animals with vitamins and trace elements during moments of increased metabolic demands, such as the transition period, is an attempt at minimizing the harmful effects of excessive reactive oxygen species (ROS) production (Politis 2012). This practice improves animals' health status and reduces disease incidence (Bourne et al. 2008; Abuelo et al. 2014b). However, this is against the organic production principles, and the European Regulation on organic farming (European Commission 2008) prohibits the use of systematic synthetic vitamin supplementation.

As OS depends on milk yield (Löhrke et al. 2004; Castillo et al. 2006) and milk production has been reported to be lower in organically managed cattle (OMC) than in conventionally managed cattle (CMC; Hamilton et al. 2002; Fall and Emanuelson 2009), it could be hypothesized that the metabolic stress associated with early lactation could be ameliorated in OMC. However, to the best of the authors' knowledge, there are no studies that have investigated the redox balance of organically managed dairy cattle. Therefore, the aim of this study was to make a preliminary assessment of the oxidative 
status of OMC during the transition period and to compare it with the oxidative status of CMC.

\section{Material and Methods}

All the experimental work was conducted in accordance with the European and Spanish legislation on the use of animals for research, and all animal use was previously approved by the Bioethical Committee of the University of Santiago de Compostela.

\section{$\underline{\text { Animals and samplings }}$}

This study is part of a larger research project (Galician Government ref. 10MRU261004PR). The preceding manuscript (Abuelo et al. 2014a) compared the different metabolic adaptation processes between $\mathrm{OMC}$ and $\mathrm{CMC}$ by means of metabolic profiling, the calculation of insulin sensitivity surrogate indices and quantification of acute phase proteins. Here, only the data regarding oxidative status will be compared. More detailed information about the animals, their husbandry, and the protocols is presented in the previous article (Abuelo et al. 2014a).

Briefly, serum samples were taken from multiparous dairy cows every 2 or 3 weeks for $\mathrm{CMC}$ and $\mathrm{OMC}$, respectively, from 2 months prior the expected calving date until the peak of lactation (expected at 75 days for $\mathrm{CMC}$ and 90 for $\mathrm{OMC}$ ). Samples from healthy periparturient cattle were obtained from one conventional farm $(n=22)$ and two organic farms ( $n=40 ; 20$ animals each) located nearby (max. distance $=40 \mathrm{~km}$ ), sharing similar soil and climate characteristics. During the whole study, the climate conditions were never too warm (average $( \pm S D)$ maximum temperature: $13.3^{\circ} \mathrm{C}( \pm 4.23)$; average $( \pm S D)$ minimum temperature: $5.1^{\circ} \mathrm{C}( \pm 2.37)$ and average $( \pm S D)$ relative humidity: $83.3 \%$ $( \pm 5.61)$ ) that the production of ROS would be increased due to heat stress (Bernabucci et al. 2002). The three farms shared similar conditions regarding feeding delivery and 
presentation; all had free-stall barns with enough number of headlocks to allow all the animals to feed together, and all have calvings all the year round. At each farm, all animals were kept under identical conditions. The diets consisted of a total mixed ration (Table 1). All feedstuff and pastures of OMC farms fulfilled the requirements on organic farming (European Commission 2008).

The CMC farm and one of the OMC had only Holstein-Friesian cows, whilst at the other OMC farm, a mixture of Holstein-Friesian $(n=12)$ and Brown-Swiss $(n=8)$ was used. Samplings of these animals were grouped ex post into the four physiological stages suggested by Van Saun (2009): (i) far-off dry (FOD): from 60 to 30 days before calving [Number of samples: 44 CMC; 48 OMC], (ii) close-up dry (CUD): from 29 days to 3 days before calving [44 CMC; $54 \mathrm{OMC}$ ], (iii) fresh (FRH): 3 to 30 days in milk [44 CMC; 49 $\mathrm{OMC}$, and (iv) peak of lactation (PkL): from 31 to 90 days in milk [71 CMC; $78 \mathrm{OMC}$ ]. Animals in the three farms were dried-off 60 days before the expected calving date, and CMC supplemented with a vitamin complex injection (Table 1).

As hitherto there are no reference intervals for oxidative status biomarkers (Celi 2011), it was necessary to establish a control group to have a baseline value to compare with the values obtained from transitional cows; therefore, animals between the fourth and fifth month of pregnancy, when the metabolic effects of pregnancy and lactation are expected to be minimal (Castillo et al. 2005), were also sampled at each farm ( $n=40$ for CMC, $\mathrm{n}=30$ for OMC -15 animals per farm-). Sampling of these animals took place simultaneously with sampling from periparturient cattle to minimize any possible temporal effect. Body condition score (BCS) of each cow was determined by the same investigator in each sampling, using a $1-5$ point scale $(1=$ lean, $5=$ obese $)$ with 0.25 intervals (Edmonson et al. 1989).

\section{$\underline{\text { Serum oxidative status determination }}$}


103 The determinable reactive oxygen metabolites were quantified as an indicator of ROS

104 with the standardized (Trotti et al. 2002) d-ROMs Test (Diacron International, Grosseto

$105 \mathrm{GR}$, Italy). This test determines hydroperoxides (breakdown products of lipids and other 106 organic substrates generated by the oxidative attack of ROS), through their reaction with 107 the chromogen N,N-diethylparaphenylenediamine. The results are expressed in arbitrary 108 'Carratelli Units' (CarrU), where 1 CarrU is equivalent to the oxidizing power of $0.08 \mathrm{mg}$ $109 \mathrm{H} 2 \mathrm{O} 2 / \mathrm{dl}$. Intra- and interassay coefficients of variation were $3.08 \%$ and $7.96 \%$, 110 respectively.

Serum antioxidant capacity (SAC) was estimated as described by Trotti et al. (2001) using the OXY-Adsorbent Test (Diacron International). This test exploits the capacity of a solution of hypochlorous acid $(\mathrm{HClO})$ to oxidize the complete pool of antioxidants in serum, and thus, SAC is a measure of the cumulative action of all the antioxidants present in serum, rather than simply the sum of measurable antioxidants. The results are expressed as $\mu \mathrm{mol} \mathrm{HClO} / \mathrm{ml}$. Intra- and interassay coefficients of variation were $2.68 \%$ and $6.89 \%$, respectively. The Oxidative Stress index (OSi) was calculated as ROS/SAC (Abuelo et al. 2013); thus, an increase in the ratio indicates a higher risk for OS due to an increase in ROS production and/or defensive antioxidant consumption.

\section{Statistical analysis}

123 Statistical analysis of the redox balance parameters during the periparturient period was performed using linear mixed models with repeated measures on JMP Pro v.11 (SAS Institute Inc., Cary, NC, USA) for the outcomes ROS, SAC, OSi and BCS. The models included the fixed effects of management type (OMC vs $\mathrm{CMC}$ ), the physiological stage

127 (FOD, CUD, FRH or PkL) and their interaction and the animal's breed. Cow was included as a random effect. A first-order autoregressive (AR(1)) covariance structure was selected in all the models based on the Akaike information criterion value. Tukey's HSD 
test was used for post hoc comparisons. To achieve a normal distribution of the residuals, the OSi was logarithmically transformed.

Within each farming system, differences between the studied physiological stages and the control group were assessed with the two-tailed Student's t-test. This test was also used to investigate whether the control groups of both managements differed. The criterion for statistical significance was established at $\mathrm{P}<0.05$.

\section{Results}

No differences were found between the two organic farms for the oxidative status biomarkers employed; hence, data of these animals were grouped together. CMC recorded always higher milk yields throughout the study than $\mathrm{OMC}$, for both early lactating and control animals (Fig. 1).

The serum concentration of ROS was significantly influenced by the management type $(\mathrm{MT})$, the physiological stage $(\mathrm{PhS})$ and their interaction $(\mathrm{PhS} \times \mathrm{MT})($ Table 2). Throughout the transition period, OMC showed significantly lower levels of pro-oxidants than CMC (Fig. 2a), which was also observed in the control groups. Although for CMC, no differences were found in the levels of ROS around calving, in the OMC, these levels increased progressively from FOD until FRH and remained stable during the PkL. However, the antioxidant capacity was significantly lower in OMC than in CMC (Fig. 2b) in all the studied stages of the transition period and also in the control animals; the levels of OMC were close to half of the values shown by $\mathrm{CMC}$ in the same period. Although the MT and the PhS $\times$ MT interaction showed a significant effect in SAC (Table 2), this variable was not influenced by the stage of the periparturient period; neither in OMC nor in CMC did the SAC show any significant difference among the studied stages of the transition from gestation to lactation. 
157 The OSi was significantly affected by the PhS, the MT and their interaction (Table 2).

158 OSi values were always numerically higher for OMC in comparison with CMC (Fig. 2c);

159 however, only during the dry period (FOD and CUD stages) were these values 160 significantly higher, being the values during the lactating stages (FRH and PkL) similar 161 in both farming systems. Noteworthy, in the close-up dry period, the values of the OSi were higher (meaning higher risk for OS) than at the beginning of the dry period in OMC, but not in CMC. Also, in the control groups, a difference was found between the two farming systems, with higher OSi values for the organic one. The breed of the animal did not influence any of the studied oxidative status markers.

BCS was significantly affected by the PhS, the MT and the PhS $\times \mathrm{MT}$, but not by the breed of the animals (Table 2). In each stage, CMC showed higher BCS than OMC (Fig. 2d), showing in both farming system a similar variation through the periparturient period: declining right after calving and increasing again afterwards.

\section{Discussion}

This study investigated the differences in the redox status of dairy cows from two organic and one conventional farm during the transition from gestation to lactation. Serum samples were taken at different time points of the transition period and compared among them, between the two farming systems at each stage and against a control group for each farming system. The differences among the different transitional stages in $\mathrm{CMC}$ have already been reported in the previous article (Abuelo et al. 2013), and here, they will only be compared with the results obtained from OMC. Although serum biomarkers do not give information about tissue localization of OS, previous research showed that serum lipid hydroperoxides, determined in this study as indicators of ROS, may be useful to predict the OS in tissues (Argüelles et al. 2004). 
184 The serum ROS levels of OMC rose progressively from the FOD until after calving and

185 remained stable thereafter. This finding has already been reported by Castillo et al.

186 (2005), who, although using different oxidative status biomarkers, found an increase in 187 pro-oxidants in the close-up period, without significant differences between this period and the one immediately following calving. They argued that this finding was a reflection of the start of the metabolic adaptation of the dairy cow for the onset of lactation several weeks before calving. After calving, milk production is responsible for the maintenance of the cellular metabolism associated with a high ROS production (Löhrke et al. 2004; Castillo et al. 2005, 2006). In fact, the ROS levels of the FRH and PkL stages were higher than those shown by the OMC control group, which also showed a lower milk yield than the early lactating cattle. adaptation for a higher milk production, which starts several weeks before calving (Bell 1995; Castillo et al. 2005). In addition, the CMC control group showed a higher concentration of serum ROS than the control group of OMC, which may also be explained by the higher milk yield in CMC (Löhrke et al. 2004; Castillo et al. 2005, 2006).

Antioxidant defenses are diverse and can be synthesized in the body, derived from the diet, or supplemented parenterally. However, this last practice is forbidden in OMC, as is the inclusion in the diet of vitamins other than those derived from raw materials occurring naturally in feedstuffs, with some exceptions considered in the European legislation requiring the previous authorization of the state member. Therefore, the maintenance of stable levels of SAC during the periparturient period whilst on the same diet and in the absence of parenteral supplementation implies that internal antioxidant 
212 production increases in response to the oxidative challenge, as found by Castillo et al.

213 (2005). However, antioxidant supplementation would surely increase the effectiveness

214 of the response (Brzezinska-Slebodzinska et al. 1994).

OMC grazed every day, and fresh green forage is an excellent source of vitamin E, whilst concentrates and stored forages, the common components of CMC diets, are generally low in this vitamin (NRC 2001). However, the SAC of OMC was, at all the studied stages, always close to half of the value shown by $\mathrm{CMC}$ at the same time point. However, this finding might be attributable to the lack of vitamin and/or trace element supplementation in the diet of OMC, while CMC received a base supplementation in the diet and a vitamin complex injection 15 days before the expected calving date, as is common practice in conventional farms to prevent and/or minimize the incidence of diseases after calving and improve the fertility of the animals and the milk quality (Politis 2012; Castillo et al. 2013).

Previous research has shown that what matters in terms of OS is the balance between pro- and antioxidants (Lykkesfeldt and Svendsen 2007; Costantini and Verhulst 2009), as OS could either be a consequence of an excessive production of ROS and/or a decrease in the body's antioxidant defence. Therefore, the joint evaluation of both components of the balance through a ratio or index is a better practice than evaluation of either component alone (Sharma et al. 1999). Thus, the OSi was calculated as the ratio between pro- and antioxidants (Abuelo et al. 2013). Unlike CMC, OMC did not receive any kind of vitamin supplementation in the pre-calving stages. Therefore, the increase in OSi shown by OMC in the FRH might be attributable to the metabolic adaptation to lactation that commences in late pregnancy, particularly in the close-up period (Castillo et al. 2005) and thereafter, similar levels were maintained due to the onset and peak of lactation. Furthermore, although in $\mathrm{CMC}$, the highest risk for OS was found during $\mathrm{PkL}$, the fact that $\mathrm{OMC}$ did not receive any extra antioxidant 
supplementation before calving increased the risk of OS in OMC to higher levels than what was observed in CMC at any of the stages from CUD onwards.

Bernabucci et al. (2005) reported that cows with higher BCS at the beginning of the dry period and those with greater loss of BCS after calving show higher ROS and lower antioxidant activity in the post-partum period. Our results are in agreement with these findings; as in comparison with $\mathrm{OMC}, \mathrm{CMC}$ always showed higher $\mathrm{BCS}$ before calving (Fig. 2d, Table 2) and a greater BCS loss after calving (data not shown), and also higher ROS (Fig. 2a, Table 2). The external antioxidant supply pre-calving to CMC impedes to assess the natural association between BCS loss and antioxidants.

Although OS is affected by milk yield due to the increased cellular metabolism and therefore ROS production (Löhrke et al. 2004; Castillo et al. 2005, 2006) and organic cattle had a lower milk production than conventional ones, when the OSi was calculated, OMC always showed a higher or similar risk of OS than CMC. Indeed, Pedernera et al. (2010) studied the oxidative status of cows in early lactation in the Australian grazing system in relation to energy balance and diet and found that the risk for OS was higher in those animals fed a diet for a lower milk production, because of a higher production of ROS. However, our results show that the higher risk of OS in organic cattle is more a consequence of the reduced antioxidant capacity than the production of ROS itself. In addition, of particular interest is the comparison between both control groups. When theoretically the cow has no major metabolic burdens, the levels of OSi, and consequently the risk of $\mathrm{OS}$, were significantly higher for $\mathrm{OMC}$ than for $\mathrm{CMC}$. This implies that this difference between OMC and $\mathrm{CMC}$ in terms of OS risk was not only related to the metabolic changes associated with the periparturient period, but also to the diet, the animals were fed and, specifically, the amount of antioxidants offered to them. The limitations of this preliminary study include the reduced number of farms involved and the differences in diet composition between OMC and CMC farms; however, to the best of our knowledge, this is the first report investigating redox balance in OMC and 
267 multinational studies comparing $\mathrm{OMC}$ and $\mathrm{CMC}$ are lacking, and studies comparing

268 OMC and CMC are usually at a regional or national level. Besides, as OMC have lower milk yields than CMC (Hamilton et al. 2002; Fall and Emanuelson 2009), their diets should meet different requirements, and therefore, the differences in their composition and nutritional value are a reflection of the management practices. The injection of a multivitamin complex to close up CMC prevents the identification of the physiological pattern of redox markers at the time of calving in these animals; but as supplementing cows with vitamins and trace elements is a common practice in conventional farms aiming to reduce post-partum disease incidence (Abuelo et al. 2014b), the results of this study compares the oxidative status of cows under the common practices of their farming system.

Thus, further studies including a larger number of animals and farms are needed to fully characterize the oxidative status of OMC for providing a better insight into the adaptation of OMC to the transition period, and study whether including natural antioxidants in the diets of OMC are need for protecting the oxidative status of organically kept cows.

\section{Conclusions}

Our results showed a significantly lower antioxidant capacity of the animals of the organic farms throughout the transition period, in comparison with the cows of the conventional the possible need of attention towards safeguarding the redox status of OMC.

Acknowledgements

This study was supported by the Galician Government (Xunta de Galicia) grants 
aspect of the study, or in writing or submitting the manuscript for publication. A. Abuelo is holder of a FPU fellowship (Ref. AP2010-0013) from the Spanish Ministry of Education, Culture and Sports. The authors gratefully thank Lucía Casanova Iglesias for her technical assistance and the owners of the farms for allowing us to perform the study and for their patience.

\section{Conflict of interest}

None of the authors of this study has a financial or personal relationship with other people or organizations that could inappropriately influence or bias the content of the study.

\section{Author contributions}

AA, JH and CC designed the study. AA collected the samples and assisted by JLB analysed them. The statistical analysis was performed by AA supervised by $\mathrm{JH}$. All authors interpreted the results. AA drafted the manuscript under the supervision of CC. All authors approved the submitted version of the paper.

\section{References}

Abuelo A, Hernandez J, Benedito JL, Castillo C, 2013: Oxidative stress index (OSi) as a new tool to assess redox status in dairy cattle during the transition period. Animal 7, 1374-1378.

Abuelo A, Hernandez J, Benedito JL, Castillo C, 2014a: A comparative study of the metabolic profile, insulin sensitivity and inflammatory response between organically and conventionally managed dairy cattle during the periparturient period. Animal 8, 1516-1525.

Abuelo A, Hernandez J, Benedito JL, Castillo C, 2014b: The importance of the oxidative status of dairy cattle in the periparturient period: revisiting antioxidant supplementation. J Anim Physiol Anim Nutr (Berl), in press. http://dx.doi.org/10.1111/ipn.12273.

Argüelles S, García S, Maldonado M, Machado A, Ayala A, 2004: Do the serum oxidative stress biomarkers provide a reasonable index of the general oxidative stress status? Biochim Biophys Acta 1674, 251-259.

Bell AW, 1995: Regulation of organic nutrient metabolism during transition from late pregnancy to early lactation. J Anim Sci 73, 2804-2819.

Bernabucci U, Ronchi B, Lacetera N, Nardone A, 2002: Markers of oxidative status in plasma and erythrocytes of transition dairy cows during hot season. J Dairy Sci 85, 2173-2179. 
Bernabucci U, Ronchi B, Lacetera N, Nardone A, 2005: Influence of body condition score on relationships between metabolic status and oxidative stress in periparturient dairy cows. J Dairy Sci 88, 2017-2026.

Bourne N, Wathes DC, Lawrence KE, McGowan M, Laven RA, 2008: The effect of parenteral supplementation of vitamin $E$ with selenium on the health and productivity of dairy cattle in the UK. Vet J 177, 381-387.

Brzezinska-Slebodzinska E, Miller JK, Quigley JD III, Moore JR, Madsen FC, 1994: Antioxidant status of dairy cows supplemented prepartum with vitamin E and selenium. J Dairy Sci 77, 3087-3095.

Castillo C, Hernández J, Bravo A, López-Alonso M, Pereira V, Benedito JL, 2005: Oxidative status during late pregnancy and early lactation in dairy cows. Vet J 169, 286-292.

Castillo C, Hernández J, Valverde I, Pereira V, Sotillo J, López Alonso M, Benedito JL, 2006: Plasma malonaldehyde (MDA) and total antioxidant status (TAS) during lactation in dairy cows. Res Vet Sci 80, 133-139.

Castillo C, Pereira V, Abuelo A, Hernandez J, 2013: Effect of supplementation with antioxidants on the quality of bovine milk and meat production. ScientificWorldJournal 2013, 616098.

Celi P, 2011: Oxidative stress in ruminants. In: Mandelker L, Vajdovich P (eds), Studies on veterinary medicine: Oxidative stress in applied basic research and clinical practice, Vol 5. Humana Press, New York, NY, USA, pp. 191-231.

Costantini D, Verhulst S, 2009: Does high antioxidant capacity indicate low oxidative stress? Funct Ecol 23, 506-509.

Edmonson AJ, Lean IJ, Weaver LD, Farver T, Webster G, 1989: A body condition scoring chart for holstein dairy cows. J Dairy Sci 72, 68-78.

European Commission, 2008: Commission Regulation (EC) No 889/2008 of 5 September 2008 laying down detailed rules for the implementation of Council Regulation (EC) No 834/2007 on organic production and labelling of organic products with regard to organic production, labelling and control. Official Journal of the European Union L250, 1-84.

Fall N, Emanuelson U, 2009: Milk yield, udder health and reproductive performance in Swedish organic and conventional dairy herds. J Dairy Res 76, 402-410.

Hamilton C, Forslund K, Hansson I, Emanuelson U, Ekman T, 2002: Health of cows, calves and young stock on 26 organic dairy herds in Sweden. Vet Rec 150, 503-508.

INRA, 2007: Alimentation des Bovins, Ovins et Caprins: Besoins des Animaux. Valeurs des Aliments. Editions Quae, Paris, France.

Löhrke B, Viergutz TT, Kanitz W, Göllnitz K, Becker F, Hurtienne A, Schweigert FJ, 2004: High milk yield in dairy cows associated with oxidant stress. Online J Vet Res 8, 70-78.

Lykkesfeldt J, Svendsen O, 2007: Oxidants and antioxidants in disease: Oxidative stress in farm animals. Vet J 173, 502-511.

NRC, 2001: Nutrient requirements of dairy cattle, 7th edn. National Academic Press, Washington, DC, USA.

Pedernera M, Celi P, García SC, Salvin HE, Barchia I, Fulkerson WJ, 2010: Effect of diet, energy balance and milk production on oxidative stress in early-lactating dairy cows grazing pasture. Vet J 186, 352-357.

Politis I, 2012: Reevaluation of vitamin E supplementation of dairy cows: bioavailability, animal health and milk quality. Animal 6, 1427-1434. 
Rizzo A, Roscino MT, Binetti F, Sciorsci RL, 2012: Roles of reactive oxygen species in female reproduction. Reprod Domest Anim 47, 344-352.

372 Sharma RK, Pasqualotto FF, Nelson DR, Thomas AJ, Agarwal A, 1999: The reactive oxygen species vs. total antioxidant capacity score is a new measure of oxidative stress to predict male infertility. Hum Reprod 14, 2801-2807.

Sordillo LM, Aitken SL, 2009: Impact of oxidative stress on the health and immune function of dairy cattle. Vet Immunol Immunopathol 128, 104-109.

Trotti R, Carratelli M, Barbieri M, Micieli G, Bosone D, Rondanelli M, Bo P, 2001: Oxidative stress and a thrombophilic condition in alcoholics without severe liver disease. Haematologica 86, 85-91.

Trotti R, Carratelli M, Barbieri M, 2002: Performance and clinical application of a new, fast method for the detection of hydroperoxides in serum. Panminerva Med 44, 37-40.

Van Saun RJ, 2009: Metabolic profiling. In: Anderson DE, Rings DM (eds), Food Animal Practice, 5th edn. W.B. Saunders, Saint Louis, MO, USA, pp. 153-162. http://dx.doi.org/10.1016/B978$\underline{141603591-6.10040-5}$ 
Table 1 Ingredients and chemical composition of the diet supplied to the animals in the farms involved in the present study.

\begin{tabular}{|c|c|c|c|}
\hline & \multicolumn{3}{|c|}{ OMC } \\
\hline & CMC & Farm A & Farm B \\
\hline Total dry matter offered & 21.7 & 15.64 & 15.49 \\
\hline Diet composition (kg DM/cow per day) ${ }^{\dagger}$ & & & \\
\hline Ryegrass hay & - & 1.90 & - \\
\hline Alfalfa hay & - & 1.88 & - \\
\hline Corn flour & - & 1.84 & - \\
\hline Grass (in pasture) & - & 6.23 & 1.31 \\
\hline Corn silage & 5.1 & - & 3.39 \\
\hline Grass silage & 4.8 & - & 6.19 \\
\hline Concentrate $^{\ddagger}$ & 11.6 & 3.79 & 4.6 \\
\hline Vitamin/mineral premix ${ }^{3,4}$ & 0.2 & - & - \\
\hline Nutrient analysis & & & \\
\hline Dry matter (\%) & 47.3 & 32.6 & 43.1 \\
\hline Crude protein (\% DM) & 17.8 & 12.7 & 11.4 \\
\hline Neutral detergent fibre (\% DM) & 30.6 & 38.0 & 40.2 \\
\hline Acid detergent fibre (\% DM) & 16.4 & 22.9 & 25.0 \\
\hline Starch (\% DM) & 31.2 & 16.2 & 14.9 \\
\hline Ether extract content (\% DM) & 4.4 & 3.0 & 2.6 \\
\hline Ashes (\% DM) & 7.3 & 7.2 & 5.9 \\
\hline PDIE (g/kg DM) & 133.5 & 87.2 & 84.0 \\
\hline PDIN (g/kg DM) & 130.9 & 84.3 & 77.8 \\
\hline Feed units milk (UFL/kg DM) & 0.94 & 0.93 & 0.86 \\
\hline
\end{tabular}

CMC: Conventionally managed cattle. OMC: Organically managed cattle. DM: dry matter; PDIE: protein supplied when energy is limited in the rumen; PDIN: protein supplied when nitrogen is limited in the rumen. UFL: 'Unité Fouragère Lait'. UFL is the net energy for lactation equivalent to $1 \mathrm{~kg}$ standard airdried barley.'

† The diet was fed as a total mixed ration and OMC animals have grazed ad libitum in pastures for 7 h/day. While indoors, lactating cows were fed ad libitum in all farms, whereas dried cows only had access to the feedbunk twice a day; although water and straw were available without restriction. The amount of grass ingested was estimated according to INRA (2007). The grass pasture composition was similar between both organic farms: Mixture of English and hybrid ryegrass with either red or balansa clover; supplementary table S1 presents the results of the chemical analysis of the pastures of both organic dairies. All the components of the diet of OMC farms fulfilled the requirements for their use in organic production under the European legislation (European Commission 2008).

‡ Concentrate composition (\% as fed): CMC Farm: rapeseed meal (26.2), corn (20.0), wheat DDGs (15.9), soybean meal (11.5), calcium soap (3.2), sugarcane (1.6), bicarbonate (1.6), calcium carbonate (0.9) and sodium chloride (0.8). OMC Farm A: barley (29.1); soybean meal (16.2), corn (15.0), peas protein concentrate (15.0), oat (10.0), wheat (10.0), sodium bicarbonate (1.0), calcium carbonate (1.7) monocalcium phosphate (1.0) and sodium chloride (0.6). OMC Farm B: barley (20.0), wheat (20.0), pea's protein concentrate (15.0), soybean expeller (10.5), oat (10\%), calcium carbonate (1.8), sodium bicarbonate $(1.0)$, monocalcium phosphate $(0.7)$, sodium chloride $(0.6)$, other minerals $(0.4)$.

${ }^{3}$ Contained: $14 \% \mathrm{Ca}, 4 \% \mathrm{P}, 6 \% \mathrm{Na}, 5 \% \mathrm{Mg}, 650000 \mathrm{IU} / \mathrm{kg}$ vitamin A, $130000 \mathrm{IU} / \mathrm{kg}$ vitamin $\mathrm{D}_{3}, 2600$ IU/kg vitamin E, 9700 ppm Zn (oxide), 8100 ppm Mn, 8100 ppm Fe, 2000ppm Cu, 100ppm I, 40 ppm $\mathrm{Cu}, 40 \mathrm{ppm}$ Se and 30 ppm Mo. 
$409{ }^{4} \mathrm{CMC}$ received 15 days before expected parturition date a vitamin complex injection (Hipravit- $\mathrm{AD}_{3} \mathrm{E}-$ 410 Forte ${ }^{\circledR}$ Hipra Laboratories, Girona, Spain) at a dose of $0.10 \mathrm{~mL} / \mathrm{kg} \mathrm{BW}$, containing each $\mathrm{mL} 75000 \mathrm{IU}$ of 411 cholecalciferol, $50 \mathrm{mg}$ of $\alpha$-tocopherol acetate and $500000 \mathrm{IU}$ of vitamin A. 
Table 2 Estimated (Est.) main effects from linear mixed models on markers of oxidative status and body condition score.

\begin{tabular}{|c|c|c|c|c|c|c|c|c|c|c|c|c|c|c|c|c|}
\hline \multirow{3}{*}{ Outcome } & \multirow{2}{*}{\multicolumn{2}{|c|}{ Intercept }} & \multicolumn{7}{|c|}{ Physiological stage (PhS) ${ }^{\ddagger}$} & \multicolumn{3}{|c|}{ Farming system $(\mathrm{MT})^{\S}$} & \multicolumn{4}{|c|}{$P$ value } \\
\hline & & & \multicolumn{2}{|l|}{ FOD } & \multicolumn{2}{|l|}{ CUD } & \multicolumn{2}{|l|}{$\mathrm{FRH}$} & PkL & \multicolumn{2}{|l|}{$\mathrm{CMC}$} & \multirow{2}{*}{$\begin{array}{l}\text { OMC } \\
\text { Est. }\end{array}$} & \multirow{2}{*}{ PhS } & \multirow{2}{*}{ MT } & \multirow{2}{*}{$\mathrm{PhS} \times \mathrm{MT}$} & \multirow[t]{2}{*}{ Breed } \\
\hline & Est. & $95 \% \mathrm{Cl}$ & Est. & $95 \% \mathrm{Cl}$ & Est. & $95 \% \mathrm{Cl}$ & Est. & $95 \% \mathrm{Cl}$ & Est. & Est. & $95 \% \mathrm{Cl}$ & & & & & \\
\hline ROS (CarrU) & 113.5 & $\begin{array}{l}108.6 \\
118.3\end{array}$ & $\begin{array}{l}- \\
13.1\end{array}$ & $\begin{array}{l}-18.5 \\
-7.8\end{array}$ & $--^{\dagger}$ & & 11.1 & $\begin{array}{l}5.6 ; \\
16.6\end{array}$ & Ref. & 26.9 & $\begin{array}{l}21.20 \\
32.50\end{array}$ & Ref. & $\begin{array}{l}< \\
0.001\end{array}$ & $\begin{array}{l}< \\
0.001\end{array}$ & 0.035 & 0.90 \\
\hline $\begin{array}{l}\mathrm{SAC}(\mu \mathrm{mol} \\
\mathrm{HClO} / \mathrm{mL})\end{array}$ & 364.4 & $\begin{array}{l}352.6 \\
376.2\end{array}$ & - & & - & & - & & Ref. & 116.3 & $\begin{array}{l}106.8 \\
125.9\end{array}$ & Ref. & 0.057 & $\begin{array}{l}< \\
0.001\end{array}$ & $<0.001$ & 0.75 \\
\hline $\log _{10} \mathrm{OSi}$ & -0.49 & $\begin{array}{l}-0.54 ;- \\
0.45\end{array}$ & $\begin{array}{l}- \\
0.05\end{array}$ & $\begin{array}{l}-0.07 \\
-0.02\end{array}$ & -0.02 & $\begin{array}{l}-0.05 \\
-0.002\end{array}$ & - & & Ref. & -0.04 & $\begin{array}{l}-0.06 ;- \\
0.02\end{array}$ & Ref. & $\begin{array}{l}< \\
0.001\end{array}$ & 0.030 & 0.010 & 0.94 \\
\hline BCS & 3.12 & $\begin{array}{l}3.07 \\
3.16\end{array}$ & - & & 0.08 & $\begin{array}{l}0.02 \\
0.14\end{array}$ & -0.09 & $\begin{array}{l}-0.15 \\
-0.03\end{array}$ & Ref. & 0.15 & $\begin{array}{l}0.11 \\
0.20\end{array}$ & Ref. & 0.002 & $\begin{array}{l}< \\
0.001\end{array}$ & $<0.001$ & 0.87 \\
\hline
\end{tabular}

413 Linear mixed models with repeated measures were built for the redox markers as outcomes with the physiological stage,

414 management type and their interaction as fixed effects and the breed of the animal as a random effect. $\mathrm{Cl}=\mathrm{confidence}$ interval.

$415{ }^{\dagger}$ - denotes that the effect was not significant $(P>0.05)$ and excluded from the model.

416 F FOD: Far-off dry (60 to 30 days before calving); CUD: Close-up dry (29 to 3 days before calving); FRH: Fresh (3 to 30 days in

417 milk); PkL: Peak of lactation (31 to 90 days in milk).

418 § CMC: Conventionally managed cattle; OMC: Organically Managed Cattle. 
Figure captions

420

421 Figure 1. Milk production of the animals of the study.

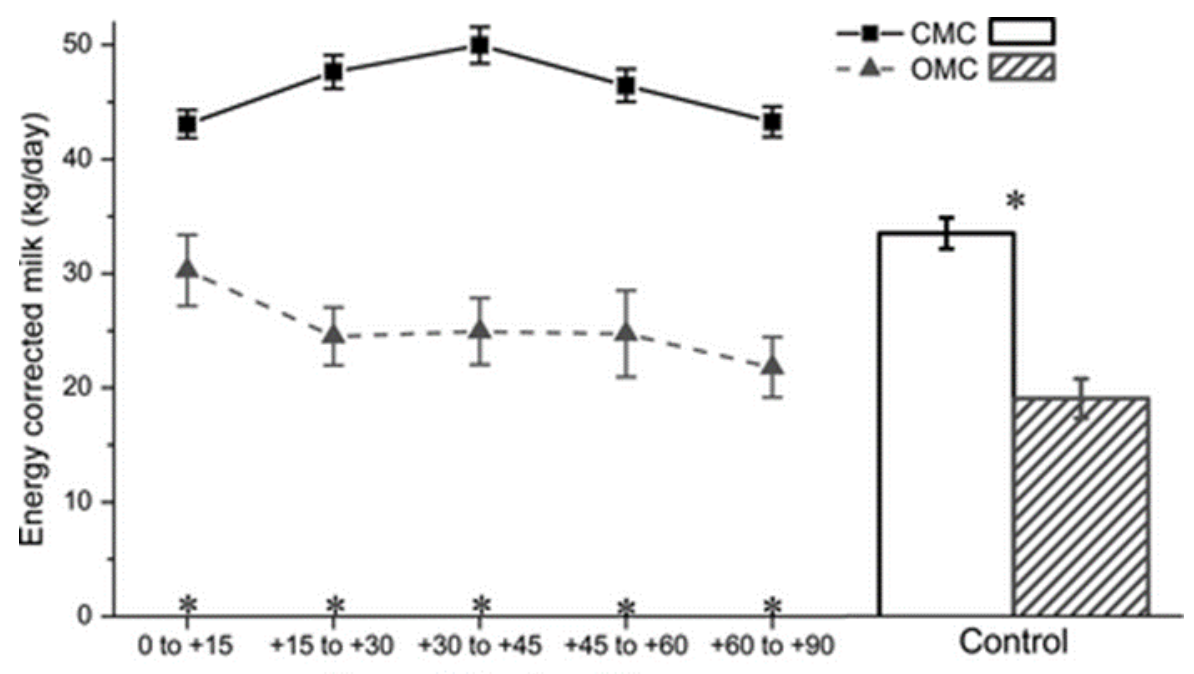

423 CMC: conventionally managed cattle; OMC: organically managed cattle; control cows (between the $4^{\text {th }}$ and $5^{\text {th }}$ months of gestation). Data are presented as mean \pm se.

425 Time points marked with an asterisk $\left(^{*}\right)$ are significantly different $(P<0.05)$. Milk yield was retrieved for each animal from the Spanish Milk Record System, considering the analysis closest to the sampling date. Milk yield was corrected based on its energy content as: energy corrected milk $(E C M ; k g)=$ milk production $(\mathrm{kg}) \times[383 \times$ fat $(\%)+$ $242 \times$ protein $(\%)+783.2] / 3140$. 
Figure 2. Levels of A- reactive oxygen species (ROS). B- serum antioxidant capacity, C- Oxidative Stress index, D- Body condition score, at the studied stages of the transition from gestation to lactation in organically and conventionally managed dairy cattle.
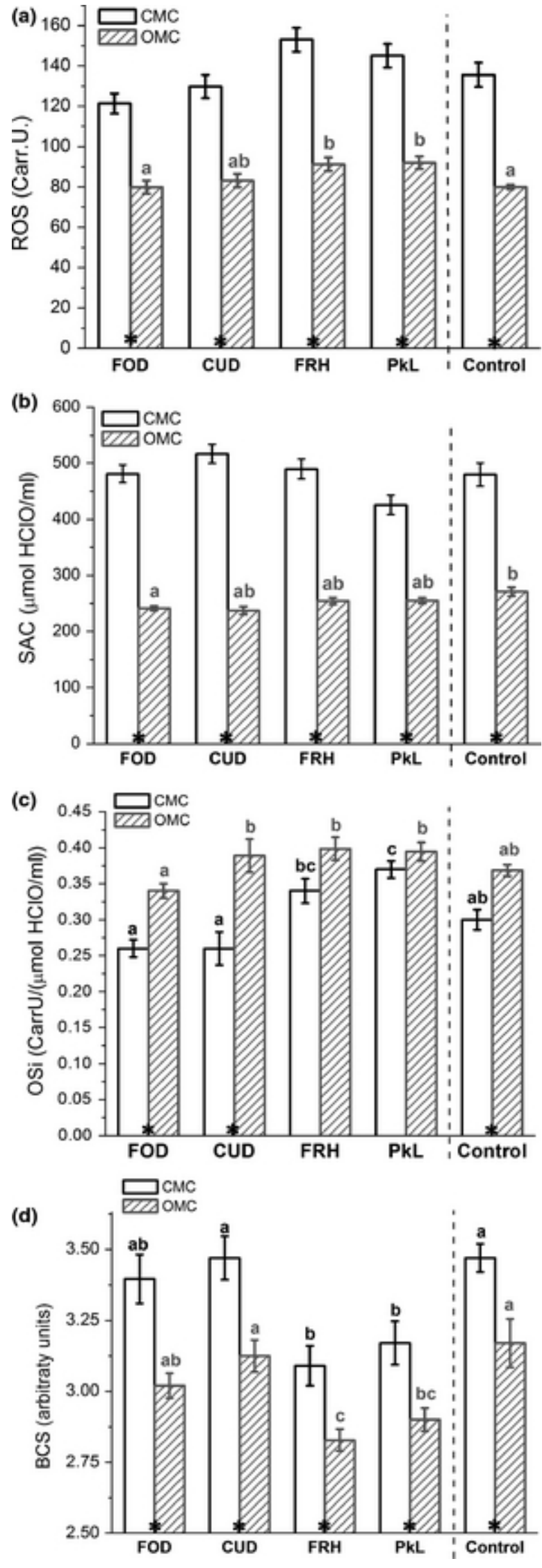

CMC: conventionally managed cattle; OMC: organically managed cattle. Data from CMC were obtained from the preceding manuscript (Abuelo et al. 2013) and reprinted with permission here. Control cows (between the $4^{\text {th }}$ and $5^{\text {th }}$ months of gestation); FOD: Far-off dry (60 to 30 days before calving); CUD: Close-up dry (29 to 3 days before calving); FRH: Fresh (3 to 30 days in milk); PkL: Peak of lactation (31 to 90 days in milk). Vertical bars represent the standard error of the mean.

a, b, c Bars with different superscript letters of the same color differ significantly $(P<0.05)$.

* Stages denoted with an asterisk indicate that the values of $\mathrm{OMC}$ and $\mathrm{CMC}$ are significantly different $(P<0.05)$. 
Table S1 Chemical composition of the pastures of the organic dairies involved in the present study.

\begin{tabular}{lll}
\hline \multirow{2}{*}{ Nutrient analysis $^{\dagger}$} & OMC & \\
\cline { 2 - 3 } & Farm A & Farm B \\
\hline Dry matter (\%) & 17.8 & 16.4 \\
Crude protein (\% DM) & 14.4 & 13.8 \\
Neutral detergent fibre - NDF (\% DM) & 46.1 & 49.8 \\
Acid detergent fibre - ADF (\% DM) & 27.8 & 31.3 \\
Ether extract content (\% DM) & 2.3 & 2.0 \\
Ashes (\% DM) & 12.4 & 10.7 \\
PDIE (g/kg DM) & 89 & 105 \\
PDIN (g/kg DM) & 96 & 120 \\
Feed units milk (UFL/kg DM) & 0.90 & 0.94 \\
Relative feed value ${ }^{\ddagger}$ & 135.7 & 120.5 \\
\hline
\end{tabular}

OMC: Organically managed cattle. DM: dry matter; PDIE: protein supplied when energy is limited in the rumen; PDIN: protein supplied when nitrogen is limited in the rumen. UFL: 'Unité Fouragère Lait'. UFL is the net energy for lactation equivalent to $1 \mathrm{~kg}$ standard air-dried barley.'

${ }^{\dagger}$ The levels of NDF were determined according to Van Soest (1981). ADF was determined in the bags containing residual NDF in an Ankom fibre analyser, according to AOAC method 973.18.10 (AOAC 1999). Ether extract content, crude protein and ashes analysis were performed following the recommendations of the European Commission (2009).

${ }^{\ddagger}$ Relative feed value (Rohweder et al. 1978) calculated as follows: [(88.9 - (0.779 x ADF\%)) $x$ (120 / NDF\%)] / 1.29. Higher values indicate higher forage quality

\section{References}

AOAC, Association of Official Agricultural Chemists, 1999: Official methods of analysis. 16th edn. AOAC Arlington, VA, USA.

European Commission, 2009: Commission Regulation (EC) No 152/2009 of 27 January 2009 laying down the methods of sampling and analysis for the official control of feed. Official Journal of the European Union. L54, 1 130.

Rohweder D. A.; Barnes R. F.; Jorgensen N., 1978: Proposed Hay Grading Standards Based on Laboratory Analyses for Evaluating Quality1. J. Anim. Sci., 47 747-759.

Van Soest P. J., 1981: Limiting factors in plant residues of low biodegradability. Agriculture and Environment, 6 135-143. 